
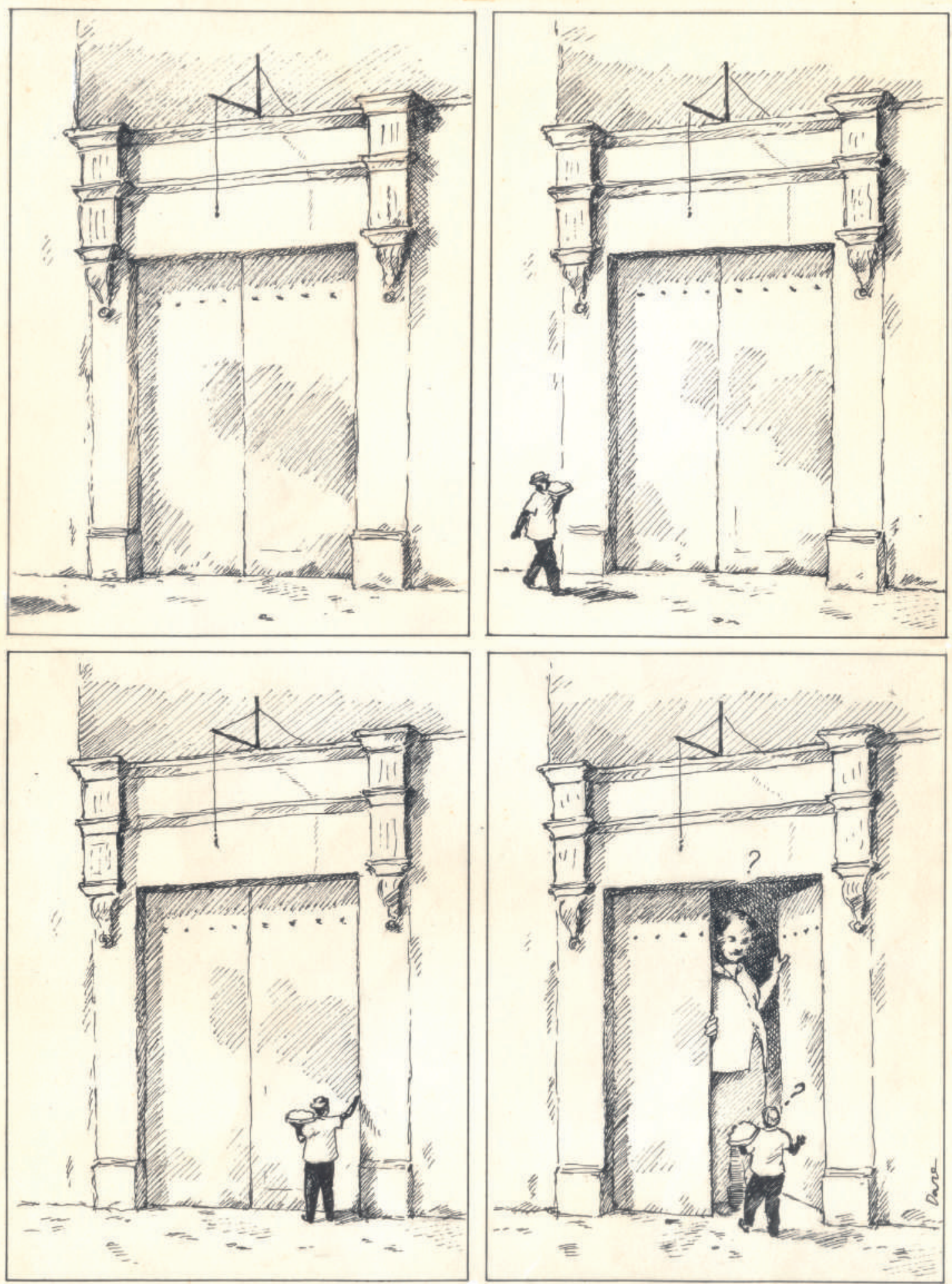


\title{
El aporte de Dare al humor gráfico en el Perú
}

\author{
Juan Acevedo \\ Investigador independiente \\ juanacevedoperu@gmail.com \\ Lima-Perú
}

\section{El Fundo Pando}

Conocí a Darko Dovidjenko, Dare (Split, 1949-Lima, 2020), en abril de 1970, en la Escuela de Artes Plásticas de la Universidad Católica, en el Fundo Pando, con chacras vecinas y al fondo la Huaca Tres Palos. Me enteré de que era yugoslavo, tenía un castellano difícil y no se esmeraba mucho en hacerse entender. Dibujaba y pintaba todo el día: esa podía ser la manera de entablar contacto con él. Un día vi que hizo unos monos humorísticos dentro de su composición de pintura. Pensé que el profesor Winternitz saltaría hasta el techo, pues en composición prefería las figuras abstractas, pero lo dejó hacer. Sin embargo, Dare tampoco era uno de los suyos, tenía su propio mundo, aparentemente no encajaba en el discurso de la Escuela. Otro día me mostró una libreta en la que hacía dibujitos de humor; algunos eran geniales, y otros, meros apuntes. Su humor era distinto al de los humoristas gráficos peruanos, ya que no le atraía lo político, sino algunas asociaciones absurdas. En ese tiempo, a mí me interesaba el humor social, pero a él ese tema lo tenía sin cuidado. Dare fumaba marihuana a diario; era pacífico y divertido sin exageraciones. Estábamos en años diferentes. Adolfo Winternitz consideró que ya había estudiado en la Universidad de Artes Aplicadas, en Split, Croacia, y le pidió que eligiera en qué año quería estar. Dare fue a segundo de Pintura. Luego lo vi enamorado de Aura Benavides, que estaba en ese taller, y pocos años después se casaron.

\section{Monos y Monadas}

La revista Monos y Monadas fue el segundo escenario en el que me encontré con Dare. Se lo presenté a Nicolás Yerovi y el 19 de febrero de 1981 debutó con su personaje, Mimo, lleno de un humor silente, onírico, con encanto. Nos recuerdo sentados alrededor de una mesa redonda; lluvia de ideas y más de risas, iqué ambiente tan dichoso! Una nueva generación de humoristas gráficos y literarios se iba sumando desde abril de 1978, burlándose de la dictadura del general Morales Bermúdez y pugnando, a su manera, para ganar mayores espacios para la democracia. ¿Qué hacía Dare allí? Lo suyo: siempre singular. Felizmente, en Monos, el humor político no lo copaba todo, y había espacios para el humor surrealista, erótico, costumbrista, filosófico, etc. Se estaba fundando, edición a edición, una nueva manera de entender el humor gráfico en el Perú. No recuerdo si Dare llegó a dibujar algo político, pero llamó la atención con su propio planteamiento. Lo que sí ocurrió fue que lo peruano fue apareciendo más en sus viñetas y secuencias. 


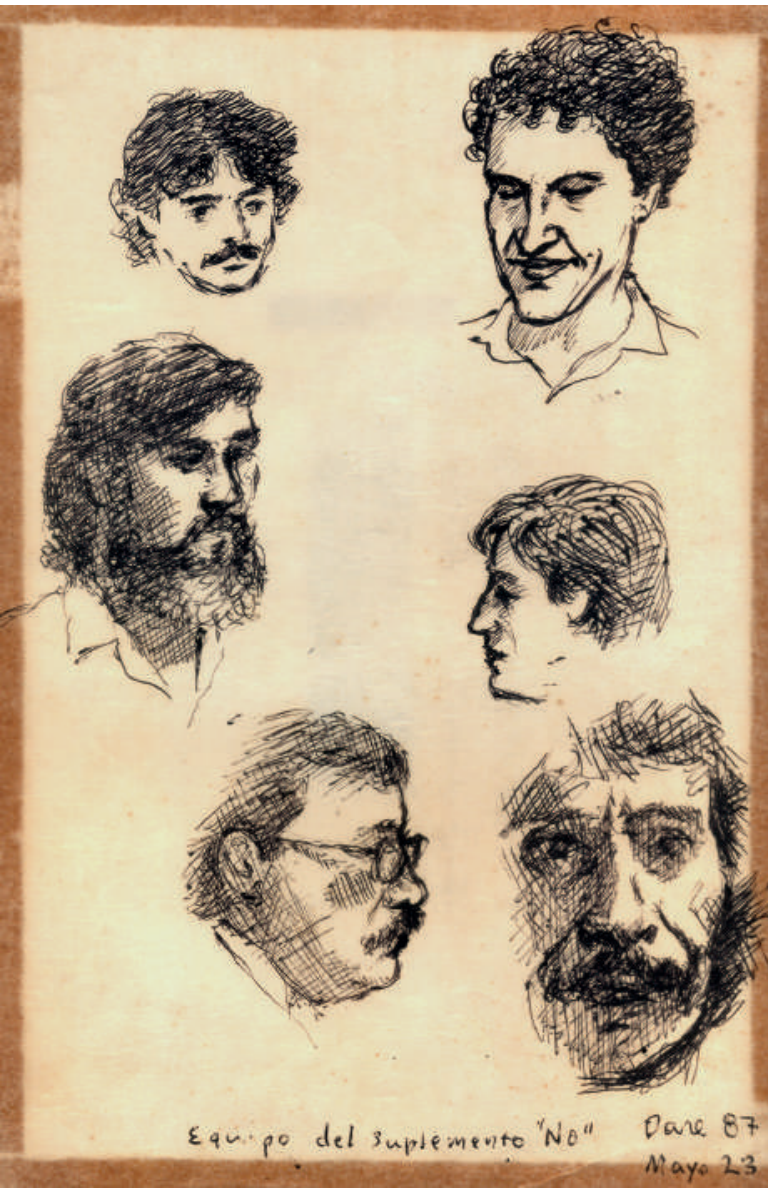

En 1984 hicimos la revista El Idiota y Dare también estuvo allí. Su participación no fue tan frecuente, pero sus secuencias tuvieron un marcado interés en el tema erótico, con un dibujo más realista, a la pluma o aguada, libre en la asociación de ideas (siempre sin palabras) y académico en el tratamiento.

\section{El suplemento iNo!}

En febrero de 1987, César Hildebrandt me encargó el suplemento iNo! de la revista Sí. Convoqué a mis amigos y creamos una publicación que fue otro hito de nuestro periodismo de humor. Dare tuvo allí una página fija a la que llamamos Delidare. Una delicatessen. A veces no tenía lo que se dice el gag que se espera del humor, el suyo era un humor distinto al de los chistes estandarizados que se importaron sobre todo de Norteamérica. Nos hicimos más amigos. Todos los sábados nos reuníamos Alonso Núñez, Pepe Sanmartín, Rafo León, Fedor Larco, Lucho Freire, Dare, Etalo Núñez, China Zöllner y yo. Los temas de Dare eran diversos, sus artes iban desde el monito plano al dibujo más elaborado, de las asociaciones sueltas al detalle riguroso, de las escenas de alcoba a las de barrio: del Centro de Lima a Miraflores, de la cita visual culta a la anotación costumbrista, pero no tanto para testimoniar una tradición, sino como motivo para el guiño de humor. El castellano de Dare, como su humor, se había peruanizado (aunque el acento no se le fue nunca). Cada semana, sin falta, Dare llegaba puntual a la reunión sabatina y cada jueves aparecía publicado Delidare. A veces no decía mucho, hacía lo que le venía en gana, su página era un lujo que nos dábamos. La gracia emergía de lo absurdo, una de sus fuentes preferidas. Otras veces recurría a las evoluciones de tamaño o forma de algo para sorprender a la lógica. El humor tiene varios mecanismos y, más allá de ellos, lo que importa es si llevan a la sonrisa (manifiesta o interior) y a la contemplación. Humor y arte. ¿Es el humor gráfico un arte? No necesariamente, pero con Dare lo fue. En junio partió a Yugoslavia, en un largo viaje marítimo, y continuó enviando sus dibujos. No sé cómo hacía para cumplir, aun desde el barco; Aura nos traía la página. Ella me pidió un día todos los dibujos de Dare y, felizmente, los tenía en orden; se los di, menos tres que él me había regalado: una secuencia (El vendedor de sanguito), una viñeta de Bedoya Reyes ("homenaje a Love Story", me dijo) y un apunte del equipo de iNo! en plena sesión. 


\section{Pachacámac y Miraflores}

Dejé de ver a Dare. Su viaje duró algunos años. Hizo varias exposiciones en Europa y volvió al Perú. Aquí estaba su hija Aura. "Más de la mitad de mi vida la he pasado en Lima", me dijo. Enviudó. Años después hizo una bella pareja con Carmen Sifuentes. Los mejores años de las revistas de humor gráfico habían pasado. Dare se fortaleció como pintor, pero el humor aparecía en algunas de sus obras. Con Ricardo Wiese, amigos desde el Fundo Pando, emprendieron una aventura que duró varios años: compartían horas pintando en Pachacámac, el santuario arqueológico más importante de la costa central. Murallas, escalinatas, plazas, restos de pintura mural prehispánica. En el desierto, bajo ese cielo: historias, mitos, ritos y hasta delitos frente al mar. Un día conversamos largo, a propósito de una entrevista que le hice en El Cuy TV, en el portal de La Mula, y sentí que antes no habíamos llegado a hablar así sobre el arte, la vida, el Perú, nuestra generación, las que venían; este Dare era un sabio, en el humor y en la seriedad, y empleaba las palabras precisas como sus temas, pinceladas y colores.

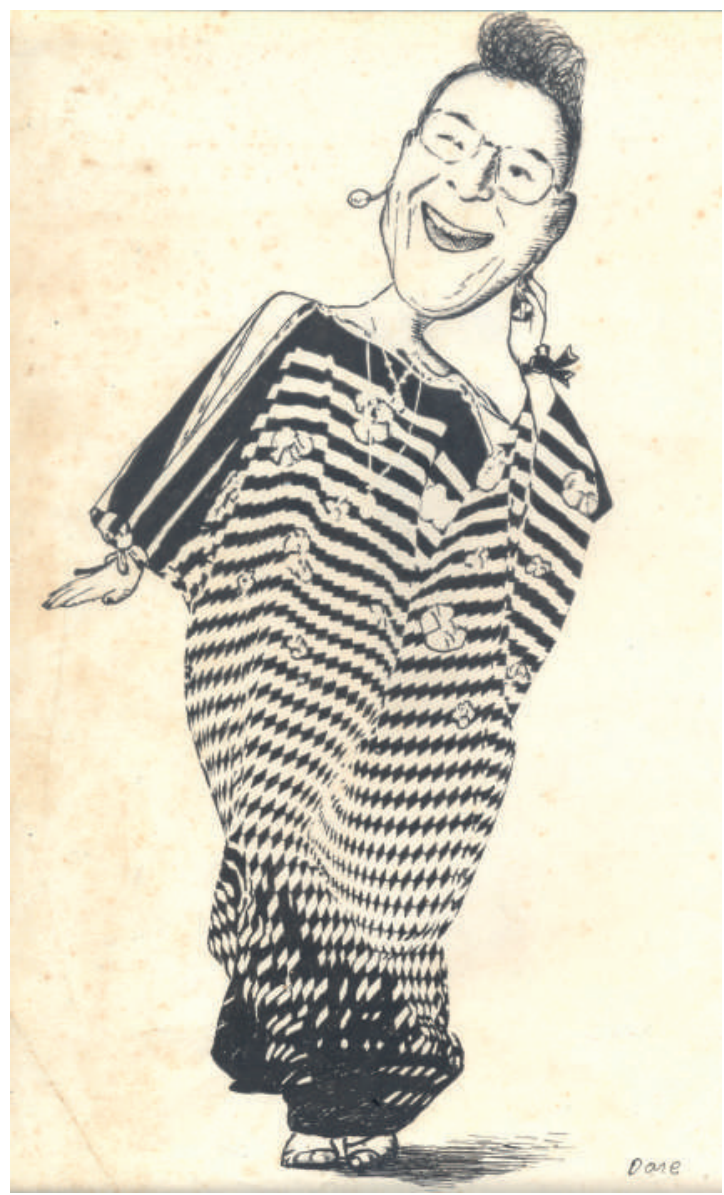

Lima, 24 de setiembre de 2020 